\title{
Endoscopic Management of Epistaxis in Lumbini Medical College
}

\author{
Anup Acharya, ${ }^{\mathrm{a}, \mathrm{d}}$ Madan Mohan Singh, ${ }^{\mathrm{b}, \mathrm{d}}$ Arati Shrestha ${ }^{\mathrm{c}, \mathrm{d}}$
}

\begin{abstract}
:
Introduction: Epistaxis is one of the commonest Ear Nose Throat (ENT) emergency. Proper guidelines for its management are lacking; on the other hand, the management is mostly done by the junior health service providers which has invited non-standardized practice of epistaxis management. Thereby this study was much inclined towards assessment of the effectiveness of endoscopic management of epistaxis. Methods: This prospective study included patients above 16 years who were diagnosed with idiopathic epistaxis visiting Out Patient of ENT Department or in the Emergency Department of Lumbini Medical College from $1^{\text {st }}$ of July 2014 to $30^{\text {th }}$ of June 2015. ENT examination was done to find the cause and site of bleeding. Thereafter different epistaxis management interventions were done depending on the bleeding condition. The data were collected, entered and then analyzed using SPSS version 21. The descriptive statistics were applied. Results: Of the total 116 patients, 53 (45.69\%) were male and 63 (54.31\%) were female showing no gender preponderance with epistaxis in our study. Majority (49\%) of the patients were managed with cauterization with silver nitrate or electrocautery in out-patient clinic. Second most common (18\%) procedure was endoscopic sphenopalatine artery cauterization. Nasal packing was done only in three cases with zero posterior pack. Conclusion: Endoscopic intervention of epistaxis seems to be safe, simple, fast, and effective for the management of epistaxis with low rates of morbidity and complications. Thereby it can be preferred over the conservative nasal packing and considered as immediate second-line management.
\end{abstract}

Keywords: electrocoagulation • epistaxis • ligation • packing • sphenopalatine

\section{INTRODUCTION:}

Epistaxis is defined as bleeding from the nasal cavities. Dry weather, use of alcohol, and use of NSAIDs have a proven association with epistaxis whereas hypertension and septal deviation do not. Epistaxis, most commonly, occurs from the Little's area in the septum. There are various modalities of management of epistaxis namely medical, cauterization, nasal packing, hot water irrigation, septal surgery, endoscopic sphenopalatine artery

a - Assistant Professor,

b - Associate Professor and Head

c - Medical Officer

d - Department of ENT Head and Neck Surgery

Lumbini Medical College, Palpa, Nepal

Corresponding Author:

Dr. Anup Acharya

e-mail: anupent@gmail.com

How to cite this article:

Acharya A, Singh MM, Shrestha A. Endoscopic management of epistaxis in Lumbini Medical College. Journal of Lumbini Medical College. 2015;3(2):38-40. doi: 10.22502/jlmc.v3i2.70
ligation(ESPAL) or cauterization, and embolization. ${ }^{1}$ Epistaxis is the second most common cause of emergency admission to ENT services. Despite of such an important condition, there are no guidelines for management, and the most junior members are often the main caregiver resulting in several areas of controversy and non-standardised practices. ${ }^{2}$

The first step in general algorithm for the management of epistaxis is assessment and resuscitation. If the site of the bleeder is identified, it is cauterized chemically or electrically. If site is not found and there is no active bleeding, patient is observed with medical treatment. With active bleeding and site not found, nasal packing is applied. If epistaxis continues despite nasal packing, further management has to be done, which includes posterior nasal packing, endoscopic sphenopalatine artery ligation, embolization etc. ${ }^{3}$

Nasal packing has been very commonly used for the management of epistaxis when bleeder is not identified on initial clinical examination. In 
a study, at a setup similar to ours, nasal packing was done in about $60 \%$ of the cases admitted for epistaxis. ${ }^{4}$ Nasal packing has been associated with many complications including pain and discomfort, swallowing difficulty, trauma to the structures while packing, pressure necrosis of the palate, alar or columellar skin, displacement with airway obstruction, sinus infection, synechia, otitis media, hypoxia, and toxic shock syndrome. Packing also requires antibiotics to prevent development of sinus infection or toxic shock syndrome., ${ }^{2,5}$

Conventionally, endoscopic intervention like ESPAL was tried after failed or unsuccessful nasal packing. ${ }^{3,6}$ With widespread popularization of endoscopic sinus surgery and a greater understanding of nasal anatomy, endoscopic control of the sphenopalatine artery has been advocated as a desirable and effective alternative for the control of posterior epistaxis. ${ }^{7,8}$ ESPAL is technically straightforward to perform, allows direct, secure ligation of the major vessel supplying the posterior nasal cavity, can be easily done under local anaesthesia in cooperative adults, avoids nasal packing, has an excellent patient tolerance, makes hospitalization if required much shorter, and has few side effects.

The aim of this prospective study was to assess the effectiveness of endoscopic management in patients with epistaxis in whom bleeding site was not localized during initial clinical examination.

\section{METHODS:}

Patients above 16 years of age coming to Out Patient of ENT Department or in the Emergency Department of Lumbini Medical College from $1^{\text {st }}$ of July, 2014 to $30^{\text {th }}$ of June, 2015 with diagnosis of idiopathic epistaxis were included in the study. On arrival, patients were assessed for Airway, Breathing, and Circulation (ABC). Patients were resuscitated, if seemed necessary, with IV fluids while waiting for the investigation reports. ENT examination was done to find the cause of bleeding. If nose was packed from the referral site, it was removed and examination done. Nose was gently packed with cotton soaked in $4 \%$ lidocaine and $0.5 \%$ oxymetazoline for 20 minutes before examination to improve the visualization of the nasal cavities.

If the bleeder was identified on initial examination, it was cauterized chemically with silver nitrate or with electrocautery. If the bleeder was not identified, patient was taken to Operation Theatre (OT) for rigid nasal endoscopy under local anaesthesia to identify the bleeder. Severely deviated nasal septum (DNS) hampering the visualization of posterior nasal cavity was corrected in the same setting under local anaesthesia. If the bleeder was identified, it was cauterized with electrocautery. If bleeder was still not identified even after thorough endoscopic nasal examination, endoscopic sphenopalatine artery cauterization was done on the side of epistaxis. We preferred local anaesthesia as it decreases the cost, does not require nil per oral status, reduces hospital stay, and avoids general anaesthesia related complications. General anaesthesia was reserved for uncooperative patients. Three $\mathrm{ml}$ (3ml) of $2 \%$ lidocaine with 1:200,000 adrenaline was injected into the pterygopalatine fossa through greater palatine foramen to anesthetize the posterior part of nasal cavities. Additional three $\mathrm{ml}$ of same solution was injected in the inferior and middle turbinates. Then the ESPA cauterization was done. Nasal packing was not done in these patients. The patients whose houses were nearby and could come anytime within 30 minutes in case of any problem occurred, were discharged after two hours of observation. Patients undergoing general anaesthesia or septoplasty with postoperative nasal pack, were admitted for 48 hours. If patient developed bleeding from the same side in this period, anterior nasal packing was done. If epistaxis persisted posteriorly, posterior and anterior nasal packing was done and patient admitted in ICU for continuous monitoring for 72 hours before packs were removed.

\section{RESULTS:}

There were a total of 116 patients included in the study. Of those, $53(45.69 \%)$ were male and 63 $(54.31 \%)$ were female. Chi-square goodness of fit test did not show a significant difference, $X^{2}(N=116$, $d f=1)=0.86, p=0.35$. Thus, there was no gender preponderance with epistaxis in our study. The mean age of all the patients was 38.67 year $(S D=11.29)$. Management modality of the cases is shown in Table 1. Majority of the patients were managed with cauterization with silver nitrate or electrocautery in out-patient clinic. Second most common procedure was endoscopic sphenopalatine artery cauterization. Nasal packing was done only in three cases with zero posterior pack. 
Table 1: Management modality of Epistaxis $(N=116)$

\begin{tabular}{lc}
\hline Modality & $\boldsymbol{n}(\%)$ \\
\hline Cauterization & $57(49.1)$ \\
\hline SPA cauterization & $21(18.1)$ \\
\hline $\begin{array}{l}\text { Endoscopic cauterization } \\
\text { Anterior nasal pack }\end{array}$ & $11(9.5)$ \\
\hline $\begin{array}{l}\text { Posterior nasal pack } \\
\text { No bleeder was identified and } \\
\text { patient refused further treatment }\end{array}$ & $3(2.6)$ \\
\hline
\end{tabular}

\section{DISCUSSION:}

In our study, there was no gender preponderance to epistaxis. Studies in different places of our country, however, showed male preponderance to this condition. ${ }^{4,9}$ We are unable to explain the cause of this difference. Half $(49.14 \%)$ of the patients with epistaxis could be managed in OPD by cauterization of visible bleeder. This emphasize the fact that a careful and meticulous clinical examination of the nose, of a patient with epistaxis, is necessary to reduce further unnecessary investigation and procedures. In our experience, preparation of the nose with $4 \%$ lidocaine solution mixed with $0.5 \%$ Oxymetazoline for 20 minutes improves the visualization of the nasal cavities.

Traditionally, for the treatment of epistaxis, if the bleeder is not identified during clinical examination, and there is active bleeding from the nose, nasal packing is done. This makes nasal packing one of a common treatment option of epistaxis despite its several complications. In a study, 10 years back, in one of the biggest hospital of our country, $60 \%$ of epistaxis were managed by nasal pack and only $2 \%$ were managed by arterial ligation. ${ }^{4}$ Even in Ninewells Hospital in United Kingdom, nasal packing is done before endoscopic intervention. ${ }^{10} \mathrm{In}$ our study we prevented nasal packing as a procedure for treatment of epistaxis to an absolute minimum i.e. three $(2.6 \%)$, thus reducing all the complications and discomfort related to nasal packing. These three cases had to be packed as there was active bleeding and operation room was not available for next few hours. There was no case of rebleed after SPA cauterization. Three out of 21 cases of shpenopalatine artery cauterization had to be done under general anaesthesia due to poor cooperation of the patients.

Two of the 24 patients who did not have active bleeding at the time of initial evaluation and refused further procedure returned with rebleed.
One was managed with endoscopic cauterization of a bleeding vessel in the posterior part of septum, the other underwent SPA cauterization under local anaesthesia. Both were discharged the same day.

The current study emphasizes on the early assessment of nasal cavities with endoscopes to localize bleeders and cauterize them. In case the bleeder is not found, sphenopalatine artery can be cauterized or ligated at the same setting. Widespread popularization and easy availability of nasal endoscopes, greater understanding of nasal anatomy, relative ease of endoscopic control of the sphenopalatine artery etc. has brought up this procedure in the hierarchy of treatment of epistaxis. ${ }^{7}$

\section{CONCLUSION:}

Endoscopic management of epistaxis is an effective method of treatment of epistaxis. It should be preferred to nasal packing due to its effectiveness, less adverse effects, less hospital stay, and direct and secure ligation of the major vessels.

\section{REFERENCES:}

1. Mcgarry GW. Epistaxis. In: Gleeson M, Browning GG, Burton MJ, Clarke R, Hibbrt J, Jones NS, et. al. (Eds). ScottBrown's Otorhinolaryngology, Head and Neck Surgery (7 Ed). Hodder Arnold, London. p.1596-1608.

2. Spielmann PM, Barnes ML, White PS. Controversies in the specialist management of adult epistaxis: an evidencebased review. Clin Otolaryngol. 2012 Oct;37(5):382-9.

3. Barnes ML, Spielmann PM, White PS. Epistaxis: a contemporary evidence-based approach. In: Smith TL(ed). Evidence based clinical practice in otolaryngology. UK. p.925-1202.

4. Adhikari P, Pradhananga RB, Thapa NM, Sinha BK. Aetiology and management of epistaxis at TU Teaching Hospital. J Inst Med. 2006;28(2):2-4.

5. Paul J, Kanotra SP, Kanotra S. Endoscopic Management of Posterior Epistaxis. Indian J Otolaryngol Head Neck Surg. 2011;63(2):141-4. DOI 10.1007/s12070-010-0054-0

6. Pritikin JB, Caldarelli DD, Panje WR. Endoscopic ligation of the internal maxillary artery for treatment of intractable posterior epistaxis. Ann Otol Rhinol Laryngol. 1998 Feb;107(2):85-91.

7. Shah AG, Stachler RJ, Krouse JH. Endoscopic ligation of the sphenopalatine artery as a primary management of severe posterior epistaxis in patients with coagulopathy. Ear Nose Throat J. 2005 May;84(5):296-7.

8. Abdelkader M, Leong SC, White PS. Endoscopic control of the sphenopalatine artery for epistaxis: long-term results. J Laryngol Otol. 2007;121:759-62. DOI:10.1017/ S0022215106003379.

9. Bhatta R. Clinical profile of idiopathic epistaxis in a hospital. J Nepal Med Assoc. 2012 Oct-Dec;52(188):167-71.

10. Barnes ML, Spielmann PM, White PS. Epistaxis: a contemporary evidence based approach. Otolaryngol Clin North Am. 2012 Oct;45(5):1005-17. DOI: 10.1016/j. otc.2012.06.018. 